\title{
Interview
}

\section{Early work on the ubiquitin proteasome system, an interview with Irwin Rose}

\author{
I Rose $e^{* 1}$ \\ 1 Department of Physiology and Biophysics, College of Medicine, University of \\ California, Irvine, CA 92697, USA \\ * Corresponding author: I Rose, Department of Physiology and Biophysics, \\ College of Medicine, University of California, Irvine, CA 92697, USA. \\ E-mail: zerose@net-star.net \\ Cell Death and Differentiation (2005) 12, 1162-1166. \\ doi:10.1038/sj.cdd.4401700
}

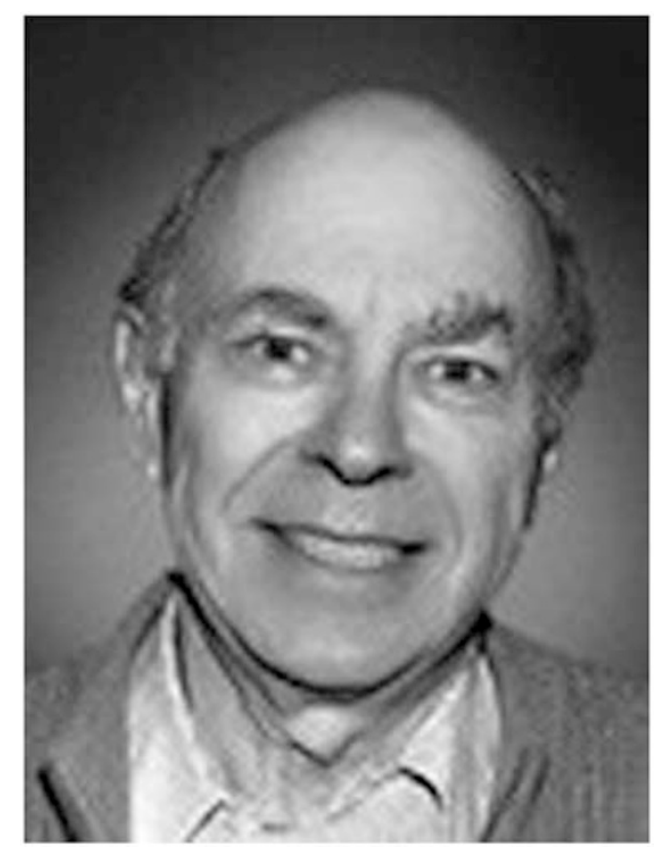

Irwin Rose was one of the first scientists working on UPS mechanisms. In particular, his early work was dedicated to the biochemistry and the role of nonlysosomal protein degradation. But how did it all begin? What triggered his scientific interest in this field from his previous work? Now a large family of related proteins exist, with interesting therapeutical potential. Here, Cell Death and Differentiation asks Irwin Rose about the early work on enzymology. This interview was obtained, thanks to the kind help of the Nobel Foundation in Stockholm, http://nobelprize.org (@) The Nobel Foundation 2004).

\section{CDD: How did you Move from your Early Family Life into your Scientific Interest?}

We left my birthplace, Brooklyn, New York in 1939 when I was 13. I enjoyed the ethnic variety and the interesting students in my public school, P.S. 134. The kids in my neighborhood were only competitive in games although unfriendly gangs tended to define the limits of our neighborhood. The major extracurricular activities that I can remember were a Victory Garden on school grounds, our contribution to the war effort, and a favorite sport, handball, played between the walls of our apartment house. Mother, Ella Greenwald, was American born into a family that included one sister and four brothers, all born in Hungary. Father, Harry Royze, had two brothers and a sister from the Odessa region of Russia. The Greenwalds and the Roses were secular Jews and the children more so although my younger brother and I spent some time in Hebrew school to please Grandfather Rose. Due to my brother having rheumatic fever the family was advised to go to a high and dry climate, Spokane, Washington, where my mother's sister had a comfortable home that could accommodate us. My father left behind to tend to his flooring business, an arrangement that I never understood and felt conflicted about. Father's visits were few and far apart. The war was going on and mother did secretarial work in the Navy Supply Depot in Spokane while we kids were making our way through the Spokane school system. I worked during the summers at a local hospital, chiefly helping out in the psychiatric ward. In time I came to see myself following some career that involved solving medical problems. No one in my family had followed a career in research. Uncle Arthur $G$ was an excellent violinist and taught cabinet making at a trade school in Brooklyn and uncle Dave $\mathrm{R}$ would have become a lawyer had the economic depression not led him into the US Internal Revenue Service. There was no one in my circle from whom I could expect to get advice. Initially, I thought problems on how the brain works to be the most interesting. But it was necessary to be practical, and concentrate on less obscure matters when I entered Washington State College. Besides, there were no courses given in neurobiology. I then went to the University of Chicago 
after a brief period in the Navy. My Ph.D. thesis problem was to determine if the DNA content of rat tissues increased if there was $B_{12}$ in the diet. This problem was suggested by my adviser based on the observation that thymine could replace vitamin $B_{12}$ in a lactobacillus. I analyzed the DNA of tissues of rats fed diets that varied in $B_{12}$. This project was doomed to failure when the genetic nature of DNA was revealed, and I found that the DNA content per cell of liver was independent of diet. ${ }^{1}$ I had to think of a new thesis project. Anxious to make up for lost time I picked a problem out of my Freshman biochemistry lecture notes. The Putnam/Evans group was interested in determining the origin of the nucleic acid components of bacteriophage synthesized in E. coli and Frank Putnam's lectures described experiments of Hammarsten, Reichard, and Saluste ${ }^{2}$ as background information. N15labeled cytosine, the free base, had been found not to be incorporated into DNA although N15 of cytosine riboside was reported to be in rat liver DNA. It was obvious for me to ask if there might be direct utilization of the whole of cytidine, ribose and all, in the biosynthesis of deoxycytidine. That would be a shock. I learned from Peter Reichard, during the 2004 reminiscence in Stockholm, that the export to Sweden of C14 was forbidden by the AEC at that time; otherwise they certainly would have done the obvious follow-up experiment using U-C14-labeled cytidine themselves. I made RNA from Euglena gracilis grown on $\mathrm{C} 14$ labeled $\mathrm{CO}_{2}$. I had to work out the determination of the independent specific activities of the sugars and bases, which I did by treating the nucleosides with nucleoside phosphorylase and hypoxanthine to exchange for the base to be analyzed. Then by paper chromatography, using a medium containing borate to retard the migration of ribosides, I could also isolate deoxyinosine and cytosine. Although U-C14 cytidine did not label the deoxyribose of E. coli DNA, I found the deoxycytidine of DNA of rat organs to be almost uniformly labeled. The $\mathrm{C} 14$ content was far in excess of the negligible radioactivity in the purine deoxynucleotides. ${ }^{3}$ Therefore, on both counts it appeared certain that the $\mathrm{C} 14$ reached the deoxyribose directly from the cytidine. Reichard repeated and extended this experiment with U-C14 uridine in 1957 with much the same result. It would have been natural for me to try to work out the enzymology of ribonucleotide reduction after graduating. Peter Reichard at Yale on a post-doc from Sweden asked me about my intentions. But I was not anxious to get embedded in such a difficult problem at this early point in my career. I do not regret this decision since it may have facilitated Reichard's beautiful work. I was interested in learning more about the principals of enzymology. Ogston's 1948 paper proposing, in effect, that the ability of an enzyme-substrate complex to distinguish between identical groups on a tetrahedral carbon was a consequence of the asymmetry of the complex, ${ }^{4}$ was a matter of hot debate in chemistry/biochemistry circles at Chicago in 1950 where the enzyme was still a black box and the emphasis was on the chemistry of changes in the substrate. In particular, the Ogston idea could justify the conclusion in the experiments of Myron Bender, done in Chemistry at the University of Chicago, that the absence of back labeling of an ester in C18 water during enzymatic hydrolysis could not rule out a tetrahedral intermediate as could be inferred from the back labeling that occurred during alkaline hydrolysis. ${ }^{5}$ In the case of the enzymatic reaction one would expect to lose all the $\mathrm{C} 18$ on the stereospecific return of the intermediate to the ester. Thus, I became challenged to establish the absolute stereochemistry of enzymatic reactions and to determine its mechanistic significance, if any. This didn't seem such a formidable task although it was not until 1963 that Kenneth Hanson and I solved the historically important problem of the prochirality of citric acid, ${ }^{6}$ which was necessary to gain a proper perspective on the aconitate hydratase reaction. In 1955, after post-doctorals at Western Reserve University with CE, Carter and at New York University with Severo Ochoa, I was fortunate to be invited by Joseph Fruton to become an Instructor in Biochemistry at Yale University Medical School. The first year at Yale was notable for two developments. Not being willing to spend the time it would take to get the Department's mass spectrometer working, I turned to the scintillation counter, which was available in the medical school lab of Seymour Lipsky, an MD with a passion for exploiting new methods. One of the pioneer instruments to become available came from a small start up company in New Haven that Lipsky had been encouraging, the Technical Instrument Company. Lipsky also had a sample of tritiated water, which together with his counter got me started on experiments I wanted to do. The second development of great note in my first year was to propose to and marry Zelda Budenstein, a graduate student in the Department. Fortunately, I caught up with her before she graduated. Her mother, widowed since Zelda was age five, came to live with us. She was a great help with the four children that were in our onrushing future. This enabled Zelda to have a research career, often paralleling mine, which she continued until 1987 when she retired to devote full time to her peace and social interests.

Probably the most interesting experiment of my 9 years at Yale (1954-1963) was interesting from the way it developed and the confidence it gave me that I might be able to do research after all. I had been looking for evidence of proton transfer in enzymes that catalyzed enolizations. Tallalay and Wang had just reported intramoleculer complete proton transfer in the keto-steroid isomerase reaction, an allylic rearrangement neighboring the ring carbonyl. We had been mistakenly unsuccessful in not finding the small amount of transfer that was later detected in the triose $P$ isomerase reaction. YJ Topper had reported that glucose-6-P isomerase in D20 formed fructose-6-P containing about one deuterium using crystallization of the barium salt as a G-6-P trap, ${ }^{7}$ suggesting that there might be no proton transfer between reactants of this enzyme. The importance of showing some transfer would be that it provided a clue to the catalytic process. Complete transfer would suggest a hydride transfer. Complete exchange would not be informative of the role of the enzyme. In unrelated experiments I observed a puzzling phenomenon. When G-6-P was used in D20, the colorimetric analysis for fructose-6-P (F-6-P) passed through a maximum before reaching a final value. I knew enough to be concerned by this overshoot of equilibrium. Julian Sturtevant of the Chemistry Department sagely asked me if I was sure of my assumptions. I soon figured out that Topper's experiment might have been misleading. In our experiment there must have been both transfer of $\mathrm{H}$ from $\mathrm{C}-2$ of the substrate to $\mathrm{C}-1$ 
of the product and exchange. As the product returned to the enzyme over time it would exchange with $D$ of the solvent. The fructose- $\mathrm{P}$ would go from a partly $\mathrm{H}$-form to an all $\mathrm{D}$-form in the labile position at $\mathrm{C}-1$. Now the only thing necessary for my strange result to make sense was an isotope effect in the color reaction for ketoses in acid. These predictions were confirmed. $^{8}$ We could show transfer using 1-T F-6-P with the isomerase using glucose-6-P dehydrogenase as a trap. We also showed that transfer was between carbons of the same molecule and that the extent of transfer was greatest at low temperature, indicating the greatest effect of heat was on the dissociation of the intermediate E-T. Since only one T entered the $\mathrm{C}-1$ position of the F-6-P at equilibrium in tritiated water, the abstraction and exchange with solvent were stereospecific. The absolute stereochemistry of this labeling could be inferred by reference to the specificity of the periodate oxidation derived T-glycolate (with glycolate oxidase and L-lactate dehydrogenase), but was rigorously established by neutron diffraction crystallography as suggested by Lindo Patterson of Fox Chase using the lithium-six salt of monodeuteroglycolate. ${ }^{9}$ This was the first example of the use of neutron diffraction to establish the absolute configuration of a molecule made asymetric by isotopic substitution. Knowing that all eight isomerases that we had examined showed intramolecular proton transfer was sufficient to establish that all cases used cis-enediol intermediates with a single conjugate acid group doing the transfer and possibly a single base removing either of the protons of the diol intermediate. ${ }^{10}$ From the stereochemistry of the cis-enediol, and the supra-position of the conjugate acid the direction of approach of the $\mathrm{C} 5-\mathrm{OH}$ in ring closing to form the aldose product could be predicted ${ }^{10-12}$ assuming no rearrangement during the process. That glucose-6-P isomerase interconverts both anomers of G-6-P suggests that the open chain aldose while on the enzyme undergoes torsion at the $\mathrm{C} 1-\mathrm{C} 2$ bond before ring closing. Bond torsion at $\mathrm{C} 2-\mathrm{C} 3$ of the enediol would explain the activation of the C2 proton of mannose-6-P, minor product of the same enzyme. ${ }^{13}$ Interconversion of the two aldoses only requires that the same torsion motion occurs at the enediol stage of the aldoses.

\section{CDD: And When did you Move to the Fox Chase and Begin the Collaboration with Avram Hershko?}

In 1963 we moved to The Institute for Cancer Research of the Fox Chase Cancer Center in Philadelphia. The Institute was a unique place, in my experience. Since its founding it was governed by the notion that to understand cancer one needed a broader understanding of biological science. In its first expansion from center city in 1949, its faculty included crystallographers, embryologists, chemists, biochemists and medical biologists without departmental restrictions. I was attracted by the chance to learn from a wide range of researchers attending each other's seminars as well as freedom from teaching. Research support came from our own competitive grants, but the Institute had a generous history of tiding you over. We were not required to go after our own salaries, which came from an NIH Core Grant, the first of its kind, which also supported institutional facilities. Decisions were made by the Director, a scientist himself, with the advice of a group of the staff and eminent outsiders. Zelda had a lab and grant of her own. In 1977 when Avram Hershko requested to share our lab space and facilities, he and his group were welcome. For the 18 years he was with us either on sabbatical or during summers. The fact that a proton exchanged slowly with the medium from the active site of many isomerases was perhaps to some extent due to the tightly bound enediolate intermediate preventing access of the abstracted proton with the solvent. However, with aconitate hydratase, a slow enzyme, we could show intermolecular T-transfer: 3-T 2 methyl isocitrate + cis-aconitate $\rightarrow 3-T$ isocitrate +2 -methyl isocitrate. ${ }^{14}$ With fumarase, a fast enzyme, we could show fumarase to be the acceptor of $T$ derived from malate depending on a relatively slow exchange of $T$ from the free enzyme. ${ }^{15}$ The D20 effect on $V_{\max }$ of fumarase is due to the slow reprotonation of the base of the free enzyme used in the hydration of fumarate ${ }^{16}$ and is independent of a slow conformational change that also limits the recycling rate. In the next few years, I started a series of investigations using isotopes to examine problems of metabolism. It had been observed by Harland Wood's group at Western Reserve that when C14 lactate or C14 glycerol are fed to a fasted animal, the labeling of the glucose units of liver glycogen is such as to suggest that triose- $P$ isomerase had failed to equilibrate its two triose phospate substrates during synthesis. This seemed unlikely given the high turnover rate of this enzyme. This question was settled by showing, with Wood's group, that the asymmetry obtained with C14-labeled glycerol in which a deuterium was present in the position abstracted in the isomerase reaction was greater in the direction predicted by the hypothesis, ${ }^{17}$ an expression of the primary isotope effect of the isomerase reaction that we had shown previously. In a whole-cell experiment, Yale graduate student Bob Kemp had examined the fate of the reducing equivalents of the reduced pyridine nucleotides labeled with $T$ during the fermentation and growth with 1- and 3-T glucose and 1-T 2-deoxyglucose in leuconostoc mesenteroides. Separate fates of the hydrides of $\mathrm{NADH}$ and $\mathrm{NADPH}$, not interchanged in the whole cell, were clearly indicated. ${ }^{18} \mathrm{NADPH}$ was the sole source for lipid synthesis during growth. In the following years I reported studies on the regulation of glucose degradation in human red blood cells, accounting for the control of the hexokinase step by varying the steady-state level of F-6-P over a 40 -fold range, ${ }^{19}$ and for the accumulation of triose- $P$ intermediates in cells incubated with high levels of orthophoshate in which rate-limiting steps in glycolysis were excluded by measuring isotope exchange rates. The low levels of NAD and pyruvate caused by net synthesis of 2,3-DPG shifted the equilibrium of the glycolytic intermediates toward high triose-Ps. ${ }^{20}$ Lowry et al. reported the rapid depletion of the normally very significant amount of glucose-1,6-P2 during mouse brain ischemia. We found that the synthetic enzyme used glucose1-P with glycerate-1,3-P2 as the phosphate donor, not ATP. ${ }^{21}$ Zelda discovered the basis for this effect of ischemia. ${ }^{22} \mathrm{~A}$ phosphatase for glucose 1,6-P2 was found with an absolute requirement for inosine-5-P, the major end product of ATP breakdown in the brain. The significance of high levels of 
glucose-1,6-P2 in the brain remains an interesting puzzle especially in view of the exceptional control properties of the synthetase ${ }^{23}$ its inhibition by lithium cation ${ }^{24}$ and the specific distribution of the enzymes of the glucose-1,6-bisphosphate system in regions of the brain and retina. ${ }^{25} \mathrm{~A}$ problem that warrants further study derives from our observation that instead of being in the cytosol most of the hexokinase of tumor and most animal cells is in the mitochondrial fraction. We showed it to be easily eluted by G-6-P. It was readily re-bound in dilute suspension using $\mathrm{Mg}^{2+}$. Bindability of enzyme to the outer membrane of the mitochondria was lost by action of a protease on the enzyme. ${ }^{26}$ It has been reported that the release of (mitochondria) hexokinase and some associated proteins may play a role in the onset of the apoptosis cascade. ${ }^{27}$ The binding property of hexokinase must be important for its coupling with the ATP generated by oxidative phosphorylation. When I felt that we understood the control of the red cell glycolytic system my attention returned to mechanism questions. ATP driven synthetases, reactions such as glutamine synthetase (gluamate $+\mathrm{NH}_{3}+\mathrm{ATP} \rightarrow$ glutamine $+\mathrm{ADP}+\mathrm{Pi}$ ) may be written in three steps: $\mathrm{ATP}+\mathrm{E} \rightarrow \mathrm{ADP}+\mathrm{E} \sim \mathrm{P}, \mathrm{E} \sim \mathrm{P}+$ glutamate $\rightarrow \mathrm{E}$. glutamyl $\sim \mathrm{P}$, E. glutamyl $\sim \mathrm{P}+\mathrm{NH}_{3} \rightarrow$ glutamine $+\mathrm{Pi}$. Negative evidence for the first step by ADP/ATP isotope exchange in the absence of glutamate and $\mathrm{NH} 3$ or for the formation of glutamyl $\mathrm{P}$ by a requirement for glutamate for ADP/ATP exchange could be misleading if ADP fails to dissociate in each case. Support for an E.ADP.Glu $\sim P$ intermediate was supposed to be preincubation of $E+{ }^{*} \mathrm{Glu}+$ ATP followed by a large amount of unlabeled $\mathrm{Glu}+\mathrm{NH}_{2} \mathrm{OH}$ produced *Gluhydroxamate. ${ }^{28}$ This latter test rested on the assumption that any E.ATP.glutamate complex would have lost the labeled glutamate more rapidly than reaction would have occurred when the $\mathrm{NH}_{2} \mathrm{OH}$ entered the complex. A similar assumption was made by Jacob Bar Tana who I met at the Hadassah Medical School in Jerusalem on our sabbatical in 1972. He was having trouble not getting reproducible results with phosphofructokinase testing for an $E \sim P$ mechanism by preincubating the enzyme with ATP32 and chasing with a mixture of F-6-P and unlabeled ATP. We agreed to explore the assumption that dissociation must be faster than chemistry on Bar Tana's next visit to the US. We used yeast hexokinase with $\mathrm{C} 14$ glucose (the pulse) followed by ATP plus a large excess of unlabeled glucose (the chase). Labeled G-6-P was formed in Michaelis proportion to the ATP in the chase up to the full measure of enzyme occupied by glucose in the pulse. Dissociation of glucose was indeed slower than its phosphorylation contrary to the generalization that chemistry is slow. Thus was demonstrated the first pulse/ chase experiment ${ }^{29}$ from which the functionality of binary complexes and their rate of dissociation could be determined. Subsequently, our lab used a pulse/chase method to find that four atoms of tritium, at the specific activity of water in the pulse have positions on the enzyme aconitate hydratase, probably an arginine-threonine pair in the active site that could be trapped by cis-aconitate. ${ }^{30}$ Although ATP/ADP exchange as a test of $E \sim P O 3$ or E-glutamyl $\sim P O 3$ intermediates would fail if the ADP did not leave the enzyme, a different kind of isotope exchange might be observed, one in which the beta-gamma bridge oxygen and the beta-nonbridge oxygens of reisolated ATP had mixed with each other. This would only require the phosphoryl oxygens of the bound ADP intermediate be capable of undergoing positional isotope exchange, PIX, depending on a symmetrical torsional motion before returning to ATP. This new exchange process was observed in a cleverly designed experiment devised by post-doc, Fred Midelfort. ${ }^{31}$ More recently we have become interested in how an enzyme recovers after product formation. Changes in the active site of an enzyme that occur when a substrate is converted to a product must be reversed before a new cycle of reaction can take place. With rare exception this recycling of the active site occurs before the product has left the enzyme and is therefore counted as part of the product-off step. Are recycling steps ordered or random? Fumarase has several properties that mark it as a rare example in which, when salt is present to accelerate the release of a product, a further sequence of steps remains that is rate limiting for the whole reaction cycle. ${ }^{32}$ Distinctive enzyme isoforms become identifiable as shown by the occurrence of noncompetitive inhibition by product analogues. ${ }^{16,33}$ Added labeled reaction product rebounds to substrate when unlabeled substrate is added showing that the product form of the enzyme is slow to recycle, the Britton counterflow effect. ${ }^{32,34}$ D20 and glycerol show noncompetitive inhibition patterns indicating that their effects occur after an irreversible step, product release. Each of these properties is rare and an indication of slow recycling. Heavy atom NMR spectroscopy of the hydrogens of P-enolpyruvate led to Mildred Cohn's solution of the enolase reaction stereochemistry using $(3 \mathrm{R})$ phosphoglyceric acid$3-D .^{35,36}$ This led us to the solution of many reaction stereochemistries using specifically labeled 3D, T-PEP. ${ }^{35}$ Our longstanding belief in enolpyruvate as the intermediate in the pyruvate kinase reaction ${ }^{37,38}$ was confirmed by chemical analysis of the active enzyme. ${ }^{39}$ Synthesis of enolpyruvate by treating D, T-PEP with phosphatase made it possible to determine the stereochemistry of pyruvate kinase ${ }^{40}$ and its role in transcarboxylase. ${ }^{41}$ In a surprise result, the Schiffs bases of dihydroxyacetone-P and of fructose-1,6 P2 were found to precipitate with the protein of muscle aldolase in cold acid. ${ }^{42,43}$ This property due to the stability of the Schiffs base intermediates in acid and the acid liability of the eneamin-Ps was used to determine their concentrations as intermediates in the aldolase reaction as the interconversion of citrate and isocitrate by aconitate hydratase was shown to occur with complete retention of the proton between $\mathrm{C} 2$ and $\mathrm{C} 3$ and no retention of the $\mathrm{OH}$ - between $\mathrm{C} 3$ and $\mathrm{C} 2$. The bound cis-aconitate intermediate must flip over, probably around a $\mathrm{CH} 2 \mathrm{C00}$-pivot, so that the enzyme bound proton can approach from the opposite faces of the intermediate in generating either of the products. ${ }^{44}$ Aconitate isomerase catalyzes the interconversion of cis- and trans-aconitate by a 1,3 allylic rearrangement that uses the (pro-S) hydrogens of the two substrates. The stereochemistry and the transfer of tritium are consistent with a carbanion mechanism. ${ }^{45}$ The physical separation of $\mathrm{H}$ - from $\mathrm{D}$-labeled molecules made possible by their different rates of reaction was used to establish that the transfer of hydrogen in glucose 6-P isomerase was intramolecular ${ }^{8}$ and that the site of attachment of $\mathrm{CO}_{2}$ to ribulose-1,5-P2 to produce two molecules of phosphoglyceric acid had to be to $\mathrm{C}-2$ rather than to $\mathrm{C}-4$ in the RUDP Carboxylase reaction. ${ }^{46}$ 


\section{CDD: What is your Present Interest, and How do you Remember your Previous Research?}

Following my retirement in 1997, Zelda and I moved to Laguna Woods in Southern California where I was able to continue lab work using space and facilities shared by Ralph Bradshaw at nearby UC Irvine. Dr James Nowick of Chemistry and I examined the mechanism of methylglyoxal synthetase (dihydroxyacetone- $\mathrm{P} \rightarrow$ methylglyoxal) trying to understand our observation $^{47}$ that the methyl group of the product was formed nonstereospecifically. We could show that the enol-aldehyde of methylglyoxal was really the enzyme's product. ${ }^{48}$ Ketonization occurs off the enzyme and therefore is nonstereospecific. It is very slow but is assisted by thiols, which interrupt the double bond conjugation by formation of a thiolhemiacetal. It was perhaps for this reason that the next enzyme, of the sequence, glyoxalase I, has the adduct of methylglyoxal with glutathione as its substrate and D-lactyl-glutathione as its product. We concluded our paper with the observation that organisms that had no glutathione would have to evolve another mechanism to dispose of methylglyoxal, which is toxic to cells due to its action in cross linking macromolecules. Our most recent study shows that the Mycobacteria that have mycothiol ( $N$-acetyl cysteine-glucosamine inositol) as the major reducing compound have indeed evolved an enzyme that carries out the same kind of sequence with a 'glyoxalase' that produces lactyl-mycothiol (unpublished). Looking back on my eclectic journey in research, I am grateful that it has gone as well as it has while remaining still not clever enough to open the black box of enzyme structure.

I am most grateful to all those who have been willing to come along with their ideas and skills. Among them were Jacob Bar Tana, Steve Benkovic, JF Biellmann, Mildred Cohn, Aaron Ciechanover, Don Creighton, Arthur Haas, Kenneth Hanson, Avram Hershko, Anthony Jaworowsky, G Kaklij, Robert Kemp, Judith P Klinman, David Kosow, Donald Kuo, Gus Lienhard, Oliver Lowry, Alton Meister, C Fred Midelfort, G Mullhofer, Koko Murakami, Edw. O'Connell, Frank Oski, Lindo Patterson, Cecile Pickart, James Robinson, Zelda Rose, Keith Schray, Steve Seeholzer, Frank Solomon, Michael Summers, Jessie Warms, Mary Wimmer, Keith Wilkinson, James Willard, and Harland Wood.

\section{References}

1. Rose IA and Schweigert BS (1952) Proc. Soc. Exp. Blot 79: 541-544

2. Hammarsten E, Reichard P and Saluste E (1950) J. Biol. Chem. 183: 105-109
3. Rose IA and Schweigert BS (1953) J. Biol. Chem. 202: 635-645

4. Ogston AG (1948) Nature 162: 963F

5. Bender ML (1951) J. Am. Chem. Soc. 73: 1626-1629; Bender ML, Heck HA (1967) J. Amer. Chem. Soc. 89: 1211-1217

6. Hanson KR and Rose IA (1963) Proc. Nati. Acad. Sci 50: 981-988

7. Topper YJ (1957) J. Biol. Chem. 225: 419-426

8. Rose IA and O'Connell EL (1961) J. Biol. Chem. 236: 3086-3092

9. Johnson CK, Gabe EJ, Tayler MR and Rose IA (1965) J. Am. Chem. Soc. 87: 1802-1804

10. Rosei A (1975) Adv. Enzymol. 43: 491-517

11. Schray KJ and Rose LA (1971) Biochemistry 10: 1058-1061

12. Rose IA, O'Connell EL and Schray KJ (1973) J. Biol. Chem. 248: 2232-2234

13. Seeholzer SH (1993) Proc. Nati. Acad. Sci. USA 90: 1237-1241

14. Rose IA and O'Connell EL (1967) J. Biol. Chem. 242: 1870-1879

15. Rose LA, Warms JVB and Kuo DJ (1992) Biochemistry 31: 9993-9999

16. Rose IA (1998) Biochemistry 37: 17651-17658

17. Rose IA, Kellermeyer R, Stjernholm R and Wood HG (1962) J. Biol. Chem. 237: 3325-3331

18. Kemp RG and Rose IA (1964) J. Biol. Chem. 239: 2998-3006

19. Rose IA and O'Connell EL (1964) J. Biol. Chem. 239: 12-17

20. Rose IA and Warms JVB (1966) J. Biol. Chem. 241: 4848-4854

21. Rose IA, Warms JVB and Kaklij G (1975) J. Blot. Chem. 250: 3466-3470

22. Guha SK and Rose ZB (1982) J. Biol. Chem. 257: 6634-6637

23. Rose IA, Warms JVB and Wong L-J (1977) J. Biol. Chem. 252: 4262-4268

24. Rose IA and Warms JVB (1980) Biochem. Biophys. Res. Corn. 92 1030-1036

25. Yip V, Pusateri ME, Carter J, Rose IA and Lowry OH (1988) J. Neurochem. 50: 594-602

26. Rose IA and Warms JVB (1967) J. Biol. Chem. 242: 1635-1945

27. Majewski N, Nogueira V, Robey RB and Hay N (2004) Mol. Cell. Biol. 24: 730-740

28. Meister A (1974) Enzymes 10: 699-714

29. Rose IA, O'Connell EJ, Litwin S and Bar Tana J (1974) J. Biol. Chem. 249: 5163-5168

30. Kuo DJ and Rose IA (1987) Biochemistry 26: 7589-7596

31. Midelfort CF and Rose IA (1977) Biochemistry 16: 1590-1596

32. Rose IA, Warms JVB and Yuan RG (1993) Biochemistry 32: 8504-8511

33. Rose IA (1997) Biochemistry 36: 12346-12354

34. Button HG (1973) Biochem. J. 133: 255-261

35. Cohn M, Pearson WE, O'Connell EL and Rose IA (1970) J. Am. Chem. Soc. 94 4095-4098

36. Rose IA, O'Connell EL, Noce P, Utter MF, Wood HG, Willard JM, Cooper TG and Benziman M (1969) J. Biol. Chem. 244: 6130-6133

37. Rose IA (1960) J. Biol. Chem. 235: 1170-1177

38. Robinson JL and Rose IA (1972); 247: 1096-1105

39. Seeholzer SH, Jawarowski A and Rose IA (1991) Biochemistry 30: 722-726

40. Kuo DJ and Rose IA (1978) J. Am. Chem. Soc. 100: 6288-6289

41. Kuo DJ and Rose LA (1982) J. Am. Chem. Soc. 104: 3235-3236

42. Rose IA and Warms JVB (1985) Biochemistry 24: 3952-3957

43. Rose IA, Warms JVB and Kuo DJ (1987) J. Biol. Chem. 262: 692-701

44. Rose IA and O'Connell EL (1967); 242: 1870-1879

45. Klinman JP and Rose IA (1971) Biochemistry 10: 2259-2266

46. Mullhofer $G$ and Rose IA (1965) J. Biol. Chem. 240: 1341-1346

47. Summers MC and Rose IA (1977) J. Am. Chem. Soc. 99: 4475-4478

48. Rose IA and Nowick JS (2002) J. Am. Chem. Soc. 124: 13047-13052 